\title{
Changing perspectives of infectious causes of maternal mortality
}

\author{
Ajay Halder ${ }^{1,2}$, Reeta Vijayselvi ${ }^{1}$, Ruby Jose ${ }^{1}$ \\ ${ }^{1}$ Department of Obstetrics and Gynecology, Christian Medical College, Vellore, India \\ ${ }^{2}$ Department of Obstetrics and Gynecology, All India Institute of Medical Sciences, Bhopal, India
}

\begin{abstract}
Objective: Infections significantly contribute to maternal mortality. There is a perceived change in the spectrum of such infections. This study aims to estimate the contribution of various types of infections to maternal mortality.

Material and Methods: We retrospectively reviewed records of maternal death cases that took place between 2003 and 2012 in the Christian Medical College, Vellore, India. The International Classification of Diseases-Maternal Mortality was used to classify the causes of deaths and World Health Organization near-miss criteria were used to identify organ dysfunction that occurred before death. Infections during pregnancy were divided into three groups, i.e., pregnancy-related infections, pregnancy-unrelated infections, and nosocomial infections.

Results: In this study, $32.53 \%$ of maternal deaths were because of some type of infection as the primary cause. The contribution of pregnancyrelated infections was comparable with that of pregnancy-unrelated infections (16.03\% vs. 16.50\%). Metritis with pelvic cellulitis, septic abortions, tuberculosis, malaria, scrub typhus, and $\mathrm{H}_{1} \mathrm{~N}_{1}$ influenza (influenza A virus subtype) were among the most commonly encountered causes of maternal death due to infections. Another $7.07 \%$ of cases developed severe systemic infection during the course of illness as nosocomial infection. A significant majority of mothers were below 30 years of age, were primiparae, had advanced gestational age, and had operative delivery. Cardiovascular and respiratory system dysfunctions were the most common organ dysfunctions encountered.

Conclusion: The contribution of pregnancy-unrelated infections to maternal deaths is significant. Control of these diverse community-acquired infections holds the key to a reduction in maternal mortality along with the promotion of clean birthing practices. Nosocomial infections should not be underestimated as a contributor to maternal mortality. (J Turk Ger Gynecol Assoc 2015; 16: 208-13)

Keywords: Infections, maternal mortality, organ dysfunction
\end{abstract}

Received: 03 July, 2015

Accepted: 14 October, 2015

\section{Introduction}

Puerperal sepsis was the most common cause of maternal death in the $19^{\text {th }}$ century, accounting for up to $50 \%$ of all maternal deaths (1). The introduction of hand hygiene and sterilization practices, followed by the use of antibiotics, resulted in a sharp fall in the incidence of sepsis. However, puerperal infections are still reported as one of the major causes of maternal death, accounting for up to $15 \%$ of deaths (2-4). Puerperal sepsis is a polymicrobial infection of the genital tract caused by bacteria that normally inhabit the birth canal (5). In contrast, the term puerperal infection is used for genital tract infection along with other generalized infections that are incidental to pregnancy, such as tuberculosis, malaria, H1N1 influenza, and other endemic infections, including scrub typhus and dengue hemorrhagic fever (5). With the growing awareness and better availability of antiseptics and antibiotics, followed by control of bacterial genital sepsis, incidental systemic infections contributing to maternal death have increased. For example, in the sub-
Saharan Africa, tuberculosis, pneumonia and meningitis, which are infections related to human immunodeficiency virus-acquired immunodeficiency syndrome (HIV-AIDS), have become major contributors to maternal mortality $(6,7)$. Poor sanitation, lack of proper housing, and poor vector control measures are the reasons for most of these vector-borne diseases.

Another important group is nosocomial infections, the contribution of which has gone unnoticed until now. With the control of delivery-associated and community-acquired infections in the Western world, hospital-acquired infections caused by resistant organisms are increasing.

Although prospective studies on genital sepsis associated with childbirth are available, there is a dearth of information regarding infections that are unrelated to pregnancy (community acquired). Nosocomial infections, which are acquired after admission to a hospital, remain largely unquantified in the south Indian population. This study aims to define the spectrum of infectious diseases that directly or indirectly contribute to maternal death in a hospital setting. 


\section{Material and Methods}

This study is a retrospective review of maternal death cases that occurred in the Christian Medical College, Vellore, India between January 2003 and December 2012. This tertiary-level teaching hospital caters to the large local population of Vellore and adjoining districts. A considerable number of women with high-risk pregnancy are referred to this center for advanced care during pregnancy and delivery from the whole of southern India and beyond. It is a privately owned faith-based institute where mostly lower-middle-class population is treated and a fair proportion (20\%-30\%) of patients is treated without cost for charity. The busy labor room has approximately eight beds for high-risk patients and 28 for low-risk patients, and there are eight beds in a high-dependency unit attached to the labor room complex. An operating room and blood bank facilities are available to support our high-output labor room, which is run by four to five postgraduate-level doctors with a proportionate number of junior doctors and staff nurses round the clock. Antenatal outpatient visits and admission and labor records are diligently maintained by on-duty staff and preserved by the medical records department. An online record of outpatient visit proceedings, investigations, and a detailed discharge summary is maintained against the patient's registration number. For this study, we identified and completed information regarding maternal death cases through a review of records from the labor room, intensive-care units, and outpatient database and discharge summaries. Maternal deaths were defined and classified according to International Classification of Diseases-Maternal Mortality (ICDMM) (8). Deaths due to infections as the primary cause were classified into pregnancy-related infection or puerperal sepsis (endometritis, peritonitis, pelvic abscess, surgical site infection, and necrotizing fasciitis) and non-pregnancy-related or incidental infections, such as malaria, tuberculosis, and pneumonia (9). Deaths were considered to be associated with hospitalacquired infection when after a primary non-infectious cause, women developed signs of severe systemic infection later during the course of illness before death (9).

Twenty-five World Health Organization (WHO) near-miss criteria (10) were used to identify organ dysfunction that occurred during the period preceding maternal death. These 25 criteria belong to three categories, namely clinical criteria, laboratory criteria, and intervention-related criteria. Each system dysfunction is identified by the presence of at least one WHO near-miss criterion specific to that system (11). Information was collected in an Epi Info ${ }^{\mathrm{TM}}$ (CDC; Atlanta, USA) database using the WHO near-miss tool (11), and statistical analysis was performed on an Excel spreadsheet (Microsoft; Washington, USA). This study was approved by the Institutional Ethics Committee and a waiver for informed consent was provided because of the retrospective nature of the study. This study was not funded.

\section{Results}

During the 10 years of the study period, there were 212 registered maternal deaths in the institute with 98,139 total births and 95,384 live births between 2003 and 2012. During this period, there were 28,788 cesarean deliveries with an average cesarean section rate of $29.33 \%$. The average perinatal mortality rate was 35.391 per 1000 live births. Only in 154 out of the 212 cases were the details provided in the records sufficient enough to extract useful information in addition to the final diagnosis. There were 84 maternal death cases that revealed severe systemic infection either as the primary cause of death or acquired during the course of illness. Table 1 shows the causes of maternal deaths that had signs of severe systemic infection. In $16.03 \%$ of maternal death cases, pregnancy-related infections were found to be the primary cause, which includes deaths due to sepsis following abortions. Metritis with pelvic cellulitis (11.79\%) was the single most important cause of pregnancy-related infection. Septic abortions were observed in $3.37 \%$ of cases. Pregnancyunrelated infections as a group were observed in $16.47 \%$ as the primary cause. Tuberculosis (4.7\%), which included pulmonary tuberculosis (eight cases) and tubercular meningitis (two cases), was the most common incidental or pregnancy-unrelated infection associated with maternal mortality. This was closely followed by malaria, H1N1 influenza, and scrub typhus with six cases (2.8\%) each. Only one mother died of AIDS-associated pneumonia. Nosocomial infections significantly contributed (7.07\%) to the morbidity of mothers as a secondary cause, all of which were defined as ventilator-acquired pneumonia.

The mean age of the women who died of infections was $23.98 \pm 4.15$ years, with more than $95 \%$ of the mothers below 30 years of age (Table 2). Approximately $60 \%$ of the women who died were pregnant for the first time, with fewer women (15.78\%) having two or more prior deliveries. Over $83 \%$ of women who died were in their third trimester of pregnancy, with more than $53.94 \%$ of women beyond 36 weeks of pregnancy. On comparing mothers with severe infection with those without

Table 1. Infectious causes of maternal mortality

\begin{tabular}{|l|c|}
\hline Pregnancy-related infection & $34(16.03 \%)$ \\
\hline Metritis with pelvic cellulitis & $25(11.79 \%)$ \\
\hline Necrotizing fasciitis & $1(0.47 \%)$ \\
\hline Chorioamnionitis & $1(0.47 \%)$ \\
\hline Septic abortion & $7(3.3 \%)$ \\
\hline Pregnancy-unrelated/Incidental infection & $35(16.50 \%)$ \\
\hline Tuberculosis & $10(4.7 \%)$ \\
\hline H1N1 influenza & $6(2.8 \%)$ \\
\hline Scrub typhus & $6(2.8 \%)$ \\
\hline Malaria & $6(2.8 \%)$ \\
\hline Dengue hemorrhagic fever & $3(1.40 \%)$ \\
\hline Typhoid & $1(0.47 \%)$ \\
\hline Herpes zoster & $1(0.47 \%)$ \\
\hline HIV with Pneumocystis carinii pneumonia & $1(0.47 \%)$ \\
\hline Orbital cellulitis & $1(0.47 \%)$ \\
\hline Hospital-acquired infection & $15(7.07 \%)$ \\
\hline Ventilator-acquired pneumonia & $15(7.07 \%)$ \\
\hline Total & $84(39.62 \%)$ \\
\hline
\end{tabular}


Table 2. Baseline characteristics

\begin{tabular}{|l|c|}
\hline Age & Total=84 (100\%) \\
\hline 20 years or less & $24(25.57)$ \\
\hline $21-30$ years & $56(66.66)$ \\
\hline More than 30 years & $4(4.76)$ \\
\hline Parity & Total=76(100\%) \\
\hline 0 & $46(60.52)$ \\
\hline 1 & $18(23.68)$ \\
\hline 2 or more & $12(15.78)$ \\
\hline Gestational age at delivery & Total=76(100\%) \\
\hline 20 weeks or less & $8(10.52)$ \\
\hline $21-28$ weeks & $5(6.57)$ \\
\hline$>28-36$ weeks & $22(28.94)$ \\
\hline More than 36 weeks & $41(53.94)$ \\
\hline
\end{tabular}

Table 3. Obstetric and perinatal outcomes

\begin{tabular}{|l|c|}
\hline Mode of termination of pregnancy & Total=82(100\%) \\
\hline Vaginal delivery & $40(48.78)$ \\
\hline Cesarean delivery & $29(35.36)$ \\
\hline Surgical abortion & $3(3.65)$ \\
\hline Complete abortion & $2(2.43)$ \\
\hline Medicated abortion & $2(2.43)$ \\
\hline Died pregnant & $5(6.09)$ \\
\hline Neonatal outcome & Total=75(100\%) \\
\hline Live birth & $48(62)$ \\
\hline Stillbirth & $27(36)$ \\
\hline Early neonatal death & $18(25)$ \\
\hline
\end{tabular}

infection, the cesarean section rate in the former group was significantly higher ( $42 \%$ vs. $29.33 \%$ ) (Table 3 ). There was a decline in the number of deaths due to septic abortion over the duration of the study period, with no such case reported in the last 3 years. Neonatal outcomes were poor, with $36 \%$ stillbirths and another $25 \%$ neonatal deaths in the next 7 days of life (Table 3 ). Table 4 shows the incidence of organ dysfunction according to the WHO near-miss criteria, where the incidence in maternal mortality cases with severe infection is compared with the incidence in the group without severe infection. Respiratory dysfunction (90.47\%) and cardiovascular dysfunction (70.23\%) remain the most common dysfunctions. Coagulation (52.38\%), hepatic (38.09\%), and renal dysfunction (33.33\%) criteria were next in the order of high incidence. There were no significant differences in the incidence of various organ dysfunctions in the infection group versus the no-infection group except in the cases of respiratory $(\mathrm{p}<0.009)$ and hepatic dysfunctions $(\mathrm{p}<0.005)$. Severe infection leading to hysterectomy (uterine dysfunction) was observed in $7.14 \%$ of women who died because of severe infection. Admission to the intensive-care unit was observed in $86 \%$ of mothers, and $54 \%$ of women received some form of blood transfusion during their stay in the hospital. The average duration (median) of hospital stay was 8 days, with 4 and 14 days as the $25^{\text {th }}$ and $75^{\text {th }}$ percentiles, respectively, whereas the average duration from delivery to death was also 8 days, with 6 and 13 days as the $25^{\text {th }}$ and $75^{\text {th }}$ percentiles, respectively.

\section{Discussion}

South Asia, including India, has observed a $63 \%$ fall in maternal mortality over the last 20 years (12). Even with this positive trend, India has contributed an estimated 50,000 maternal deaths, which is approximately $72 \%$ of maternal deaths in South Asia in the year 2013. Direct causes of maternal death remain the most important causes, constituting approximately $50 \%$ of all maternal deaths (13). Obstetric hemorrhage, hypertensive disorders of pregnancy, puerperal sepsis, and abortion-related deaths are the most important direct causes (14). All direct causes of maternal mortality are considered preventable; however, pregnancy-related infections (puerperal sepsis) have the highest case fatality ratio among them (15). There are three major groups into which infections in pregnancy have been traditionally classified, namely pregnancy-related infection, pregnancy-unrelated or incidental infection, and nosocomial infection (9). We found that $16.07 \%$ (34/212) of maternal deaths were due to pregnancy-related infections in our study, which includes $3.37 \%$ deaths due to septic abortions. Being mainly related to the cleanliness of the birthing environment, a reduction in pregnancy-related infection could be achieved after the introduction of antisepsis and antibiotics. In a large multicenter study (12) of 7065 sites and 188 countries that evaluated the causes of maternal deaths from 1990 to 2013, there was a reduction in maternal deaths due to sepsis from $12 \%$ to $9 \%$. The clean birthing practices campaign, (16) training programs for skilled birth attendants, and promotion of institutionalized deliveries (Janani Suraksha Yojana) are some of the measures in India that played a pivotal role in bringing the puerperal sepsis rate down (17). Having said that, several large-scale multicenter studies have revealed that there is as much as a 50 -fold difference in puerperal sepsis rates across centers in Africa and Asia (18). This is because of the lack of a standard definition and under reporting of sepsis cases $(19,20)$. Most of the studies from low- and middle-income countries are hospital based, which is not a true representation of the community. There is further under reporting because of the fact that early discharge of patients occurs as a result of a shortage of hospital beds and because puerperal fever typically only occurs $24-72 \mathrm{~h}$ after delivery, when women have already been discharged.

Chuang et al. (21), in their study of 220 cases of puerperal sepsis, found bacteremia associated with Group A streptococcus (GAS) to be the most common clinical presentation, followed by endometritis, peritonitis, necrotizing fasciitis, and toxic shock syndrome, in that order. Bacteremia with GAS organisms without any foci was not encountered in our cases of maternal deaths because it is amenable to treatment by potent antibiotics, and thus, is not fatal. The proportion of other clinical presentations of genital sepsis is similar to that of Chuang et al. (21). Studies $(5,22,23)$ have identified several obstetric risk factors for puerperal sepsis, such as pre-labor rupture of membranes, prolonged 
Table 4. Organ dysfunction in maternal mortality cases (infected versus non-infected group)

\begin{tabular}{|c|c|c|c|}
\hline \multirow{3}{*}{$\begin{array}{l}\text { WHO Organ Dysfunction Criteria } \\
\text { Cardiovascular dysfunction shock, use of continuous } \\
\text { vasoactive drugs, cardiac arrest, cardiopulmonary } \\
\text { resuscitation, severe hypoperfusion (lactate } \\
>5 \mathrm{mmol} / \mathrm{L} \text { or }>45 \mathrm{mg} / \mathrm{dL} \text { ), or severe acidosis }(\mathrm{pH}<7.1 \text { ) }\end{array}$} & \multirow{2}{*}{\multicolumn{2}{|c|}{$\begin{array}{c}\text { Incidence of organ dysfunction } \\
\text { Infected group }(\mathrm{t}=84) \text { versus non-infected } \\
\text { group }(\mathrm{t}=68) \\
\text { Total incidence }(\% \text { with } 95 \% \mathrm{CI})\end{array}$}} & \multirow[b]{3}{*}{$\mathrm{p}=0.083$} \\
\hline & & & \\
\hline & $\begin{array}{c}70.23 \\
(60.45-80.01)\end{array}$ & $\begin{array}{c}82.35 \\
(73.35-91.41)\end{array}$ & \\
\hline $\begin{array}{l}\text { Respiratory dysfunction acute cyanosis, gasping, } \\
\text { severe tachypnea (respiratory rate }>40 \text { bpm), severe } \\
\text { bradypnea (respiratory rate }<6 \text { bpm), severe hypoxemia } \\
\left(\mathrm{PaO}_{2} / \mathrm{FiO}_{2}<200, \mathrm{O}_{2} \text { saturation }<90 \% \text { for } 60 \text { min), }\right. \\
\text { or intubation and ventilation }\end{array}$ & $\begin{array}{c}90.47 \\
(85.2-95.74)\end{array}$ & $\begin{array}{c}76.47 \\
(68.01-84.93)\end{array}$ & $\mathrm{p}=0.009$ \\
\hline $\begin{array}{l}\text { Renal dysfunction oliguria non-responsive to fluids } \\
\text { or diuretics, dialysis for acute renal failure, or severe } \\
\text { acute azotemia (creatinine }>3.5 \mathrm{mg} / \mathrm{dL} \text { ) }\end{array}$ & $\begin{array}{c}33.33 \\
(24.87-41.79)\end{array}$ & $\begin{array}{c}41.17 \\
(31.35-50.99)\end{array}$ & $\mathrm{p}=0.159$ \\
\hline $\begin{array}{l}\text { Coagulation dysfunction failure to form clots, massive } \\
\text { transfusion of blood or red cells ( } 5 \text { units), or severe acute } \\
\text { thrombocytopenia ( }<50,000 \text { platelets } / \mathrm{mL})\end{array}$ & $\begin{array}{c}52.38 \\
(43.42-61.34)\end{array}$ & $\begin{array}{c}50 \\
(40.03-59.97)\end{array}$ & $\mathrm{p}=0.385$ \\
\hline $\begin{array}{l}\text { Hepatic dysfunction jaundice in the presence of } \\
\text { pre-eclampsia, severe acute hyperbilirubinemia } \\
\text { (bilirubin }>6.0 \mathrm{mg} / \mathrm{dL} \text { ) }\end{array}$ & $\begin{array}{c}38.09 \\
(29.37-46.81)\end{array}$ & $\begin{array}{c}19.11 \\
(11.27-26.95)\end{array}$ & $\mathrm{p}=0.005$ \\
\hline $\begin{array}{l}\text { Neurological dysfunction prolonged unconsciousness/coma } \\
\text { (lasting }>12 \mathrm{~h} \text { ), stroke, status epilepticus/uncontrollable } \\
\text { fits, or total paralysis }\end{array}$ & $\begin{array}{c}23.81 \\
(16.17-31.45)\end{array}$ & $\begin{array}{c}20.58 \\
(12.52-28.64)\end{array}$ & $\mathrm{p}=0.317$ \\
\hline $\begin{array}{l}\text { Uterine dysfunction hemorrhage or infection leading } \\
\text { to hysterectomy }\end{array}$ & $\begin{array}{c}7.14 \\
(2.52-11.76)\end{array}$ & $\begin{array}{c}11.16 \\
(4.88-17.44)\end{array}$ & $\mathrm{p}=0.193$ \\
\hline
\end{tabular}

labor, multiple vaginal examinations (more than five), obstetrical maneuvers, anemia, primiparity, and poor nutrition. However, the single most important factor associated with infection is operative delivery. In this study, the cesarean section rate in maternal mortality cases with infection was $42 \%$ compared with $29.33 \%$ in cases without infection. It was further found by Smaill et al. (23) that endometritis is associated more with emergency cesarean section than with elective surgery. Rising trends in obesity and gestational diabetes are increasingly contributing to puerperal sepsis in the form of surgical site infections (24).

Infections unrelated to pregnancy are community-acquired infections, such as pulmonary tuberculosis, malaria, HIV-AIDS, H1N1 influenza, and other endemic infections, such as dengue hemorrhagic fever and scrub typhus. Estimates of the contribution of these infections to indirect causes or indeterminate causes remain largely unknown (25). Unrelated infections as a group were found to have claimed $16.47 \%$ (35/212) lives in this study, which is similar to pregnancy-related infections. Among all these incidental causes, tuberculosis remains the most important cause of death in the Indian subcontinent. In an estimate from 1999 (26), death due to tuberculosis was observed in more women in their reproductive age group (15-45 years) than all causes of maternal mortality put together. If diagnosed early and treated with multi-drug antitubercular treatment, the outcome in infected women is as good as in women without the disease. In contrast, with late treatment or no treatment, there is a high incidence of fetal growth restriction, preterm labor, and perinatal loss, along with increased maternal mortality and morbidity $(27,28)$. After tuberculosis, malaria is the second most common infection resulting in pregnant women dying worldwide. In sub-Saharan Africa, almost 25\% of maternal deaths can be attributed to malaria or malaria complicated by HIV-AIDS (29). Pregnant women are three times more likely to suffer from a severe disease and have a 50\% increase in mortality associated with it $(30,31)$. Primiparae are more likely to suffer from adverse maternal outcomes due to severe anemia and cardiac failure during labor, whereas multiparous women have milder maternal symptoms but suffer from disproportionately high perinatal morbidity and mortality due to innate immunity and placental sequestration of malarial parasites (30, 32).

This institution witnessed six clustered cases of maternal deaths with polymerase chain reaction-positive H1N1 influenza during the pandemic, which started in 2009 and peaked in 2011. In India, the largest numbers of deaths were reported during the same period (33). Pregnant women are at an increased risk of severe respiratory morbidity and mortality and adverse perinatal outcomes (34-36). Late recognition, delay in initiating antiviral treatment, and the presence of comorbid conditions, such 
as asthma and diabetes, were found to increase morbidity and mortality (37).

Scrub typhus is a zoonosis that is endemic to the Asia-Pacific region (38). It is poorly studied in the Indian subcontinent and its contribution to maternal death remains unmeasured. In a case series by Mahajan (39), five pregnant women diagnosed with scrub typhus were studied. One woman died of multi-organ failure. In this study, there were six maternal deaths attributable to scrub typhus during the 10-year period. The disease mainly presents as rash, fever, myalgia, and lymphadenopathy. Complications that develop after a week include jaundice, septic shock, pneumonitis, myocarditis, and meningoencephalitis (39).

There were four HIV-positive women who died during these 10 years in our hospital, but only one death could be attributed to an HIV-AIDS-related complication (Table 1). For Tamil Nadu (a southern state in India), which is considered to have a high prevalence of HIV, this finding appears biased (40). A possible explanation is that being a privately owned institute, there are fewer HIV-positive women registered in our hospital because the Indian government provides antiretroviral therapy and all delivery services to these mothers free of cost in public-sector hospitals. After the increase in coverage of antiretroviral therapy, there is reduced HIV-related mortality among pregnant women (41).

The concept of near miss has led to the appreciation of all events that follow the primary cause leading to severe maternal outcomes. In this context, we could focus on the fact that many patients who have obstetric hemorrhage or pregnancy-induced hypertension as the primary cause end up in an intensive-care unit for a long time and may develop a nosocomial infection. Ventilator-associated infections are the most serious among these, others being urinary tract infections, bedsores, etc. The contribution of hospital-acquired infections to morbidity and mortality specific to pregnancy is largely unknown. This study estimated that $7.07 \%$ (15/212) of women developed a nosocomial infection before they died. All of these had ventilator-associated pneumonia as a nosocomial infection in this study. With the increase in hospital deliveries, increasing use of antibiotics, and widespread availability of intensive-care unit facilities, nosocomial infections are on the rise and will continue adversely affecting outcomes unless kept in check.

Organ dysfunction criteria are used to access the severity of the maternal disease and prevent severe maternal outcomes (42). Cardiovascular and respiratory dysfunctions are the most commonly encountered organ dysfunctions: $70.23 \%$ and $90.47 \%$, respectively, in mothers who died of severe infection. The organ dysfunctions that were significantly different from the noninfected group are respiratory dysfunction $(90.47 \%$ vs. $76.47 \%$ $\mathrm{p}<0.009)$ and hepatic dysfunction (38.09\% vs. $19.11 \% \mathrm{p}<0.005)$. The first finding may be because of many infections specific to the respiratory system, such as tuberculosis and H1N1 influenza, whereas the second observation is because of more chances of multi-organ dysfunction in the puerperal infection group.

In conclusion, infections during pregnancy continue to be a major contributor to maternal mortality, although the proportions of causes are changing. Pregnancy-unrelated or incidental infections are as important, if not more so, as a contributor to maternal mortality compared with genital sepsis. Along with clean birthing practices and the use of prophylactic and therapeutic antibiotics, the fight has to be continued against tuberculosis and vector-borne diseases to avert these preventable maternal deaths. Awareness, primary prevention, early diagnosis, and treatment are required to control seasonal and epidemic diseases, such as malaria, H1N1 influenza, and dengue. Education, prevention of anemia, food fortification, and a midday meal program in schools will pay sustained dividends by ensuring that girls become stronger mothers of tomorrow.

Limitations of the study, records were deficient in being able to provide complete data. The diseases were diagnosed with methods that were available at the time and at times, on the clinical decision of the treating physician. Therefore, the classification of deaths according to a specific causative agent is less than accurate.

Ethics Committee Approval: Ethics committee approval was received for this study from the ethics committee of Christian Medical College Vellore, India.

Informed Consent: Exemption from informed consent was received from Ethics committee as it was a retrospective review of death records which took place over a decade.

Peer-review: Externally peer-reviewed.

Author Contributions: Concept - A.H., R.J.; Design - A.H., R.J.; Supervision - A.H., R.J., R.V.; Resource - A.H., R.V.; Materials A.H., R.J., R.V.; Data Collection and/or Processing - A.H., R.J., R.V.; Analysis and/or Interpretation - A.H., R.J., A.H., R.V.; Writing - A.H., R.J.; Critical Reviews - A.H., R.J., R.V.

Conflict of Interest: No conflict of interest was declared by the authors.

Financial Disclosure: The authors declared that this study has received no financial support.

\section{References}

1. Loudon I. Death in childbirth: An international study of maternal care and maternal mortality. Oxford: Clarendon Press; 1992. p. 1800-950. [CrossRef]

2. Khan KS, Wojdyla D, Say L, Gülmezoglu AM, Van Look PF. WHO analysis of causes of maternal death: a systematic review. Lancet 2006; 367: 1066-74. [CrossRef]

3. Ronsmans C, Graham WJ; Lancet Maternal Survival Series steering group. Maternal mortality: who, when, where, and why. Lancet 2006; 368: 1189-200. [CrossRef]

4. Schutte JM, Steegers EA, Schuitemaker NW, Santema JG, de Boer $\mathrm{K}$, Pel M, et al. Rise in maternal mortality in the Netherlands. BJOG 2010; 117: 399-406. [CrossRef]

5. Maharaj D. Puerperal pyrexia: a review. Part I. Obstet Gynecol Surv 2007; 62: 393-9. [CrossRef]

6. Black V, Brooke S, Chersich MF. Effect of human immunodeficiency virus treatment on maternal mortality at a tertiary center in South Africa: a five year audit. Obstet Gynecol 2009; 114: 292-9. [CrossRef]

7. Van Dillen J, Meguid T, van Roosmalen J. Maternal mortality audit in a hospital in Northern Namibia: the impact of HIV/AIDS. Acta Obstet Gynecol Scand 2006; 85: 499-500. [CrossRef]

8. The WHO Application of ICD-10 to deaths during pregnancy, child $\neg$ birth and the puerperium: ICD-MM. Available from: 
http://www.who.int/reproductivehealth/publications/monitoring/9789241548458/en/

9. Paruk F. Infections in obstetrical critical care. Best Prac Res Clin Obstet Gynaecol 2008; 22: 83-6. [CrossRef]

10. Pattinson R, Say L, Souza JP, Broek N, Rooney C. WHO maternal death and nearmiss classifications. Bull World Health Organ 2009; 87: 734. [CrossRef]

11. Say L, Souza JP, Pattinson RC; WHO working group on Maternal Mortality and Morbidity classifications. Maternal near miss - towards a standard tool for monitoring quality of maternal health care. Best Pract Res Clin Obstet Gynaecol 2009; 23: 287-96. [CrossRef]

12. GBD 2013 Mortality and Causes of Death Collaborators. Global, regional, and national age-sex specific all-cause and cause-specific mortality for 240 causes of death, 1990-2013: a systematic analysis for the Global Burden of Disease Study 2013. Lancet 2015; 385: 11771. [CrossRef]

13. Maternal mortality: Fact sheet $\mathrm{N}^{\circ} 348$. World Health Organization. WHO. Available from: http://www.who.int/mediacentre/factsheets/ fs348/en/

14. Halder A, Jose R, Vijayselvi R. Maternal mortality and derivations from the WHO near-miss tool: An institutional experience over a decade in Southern India. J Turk Ger Gynecol Assoc 2014; 15 : 222-7. [CrossRef]

15. Dolea C, Stein C. Global burden of maternal sepsis in the year 2000. Evidence and information for policy. Geneva: World Health Organization; 2003.

16. Seward N, Osrin D, Li L, Costello A, Pulkki-Brännström A-M, Houweling TA, et al. Association between Clean Delivery Kit Use, Clean Delivery Practices, and Neonatal Survival: Pooled Analysis of Data from Three Sites in South Asia. PLoS Med 2012; 9: e1001180. [CrossRef]

17. Shiffman J, Ved R. The state of political priority for safe motherhood in India. BJOG 2007; 114: 785-90. [CrossRef]

18. Streatfield PK, Alam N, Compaoré Y, Rossier C, Soura AB, Bonfoh $\mathrm{B}$, et al. Pregnancy-related mortality in Africa and Asia: evidence from INDEPTH Health and Demographic Surveillance System sites. Global Health Action 2014; 7: 25368. [CrossRef]

19. Hogan MC, Foreman KJ, Naghavi M, Ahn SY, Wang M, Makela SM, et al. Maternal mortality for 181 countries, 1980-2008: a systematic analysis of progress towards Millennium Development Goal 5. Lancet 2010; 375: 1609-23. [CrossRef]

20. Hill K1, Thomas K, AbouZahr C, Walker N, Say L, Inoue M, et al. Estimates of maternal mortality worldwide between 1990 and 2005: an assessment of available data. Lancet 2007; 370: 1311- 9. [CrossRef]

21. Chuang I, Van Beneden C, Beall B, Schuchat A. Population-based surveillance for post -partum invasive group a streptococcus infections, 1995-2000. Clin Infect Dis 2002; 35: 665-70. [CrossRef]

22. Kramer HM, Schutte JM, Zwart JJ, Schuitemaker NW, Steegers EA, van Roosmalen $\mathrm{J}$ et al. Maternal mortality and severe morbidity from sepsis in the Netherlands. Acta Obstet Gynecol 2009; 88: 64753. [CrossRef]

23. Smaill FM, Gyte GML. Antibiotic prophylaxis versus no prophylaxis for preventing infection after cesarean section. Cochrane Database Syst Rev 2010: CD007482. [CrossRef]
24. Acosta C, Bhattacharya S, Tuff nell D, Kurinczuk J, Knight M.Maternal sepsis: a Scottish population-based case-control study. BJOG 2012; 119: 474-83. [CrossRef]

25. Conroy AL, McDonald CR, Kain KC. Malaria in pregnancy: diagnosing infection and identifying fetal risk. Expert Rev Anti Infect Ther 2012; 10: 1331-42. [CrossRef]

26. World Health Organisation; World Health Report; 1999. Available from: http://www.who.int/whr/1999/en/whr99_en.pdf

27. Figueroa-Damien R, Arredondo-Garcia JL. Pregnancy and tuberculosis: influence of treatment on perinatal outcome. Am J Perinatol 1998; 15: 303-6. [CrossRef]

28. Good JT, Iseman MD, Davidson PT, Lakshminarayan S, Sahn SA. Tuberculosis in association with pregnancy. Am J Obstet Gynecol; 1981; 140: 492-8.

29. Menéndez C, Romagosa C, Ismail MR, Carrilho C, Saute F, Osman $\mathrm{N}$. et al. An autopsy study of maternal mortality in Mozambique: the contribution of infectious diseases. PLoS Med 2008; 5: e44. [CrossRef]

30. Monif GRG, Baker DA. Infectious Disease in Obstetrics and Gynecology. New York: Parthenon; 2004. p. 280-6.

31. World Health Organization. Guidelines for the Treatment of Malaria. Geneva: World Health Organization; 2015. p. 89.

32. Desai M, ter Kuile FO, Nosten F, McGready R, Asamoa K, Brabin B, Newman RD. Epidemiology and burden of malaria in pregnancy. Lancet Infect Dis 2007; 7: 93-104. [CrossRef]

33. Ministry of Health and Family Welfare, India. Information on Swine Flu. New Delhi: MOHFW. Available from: http://www. mohfw.nic. in/swineflu.htm

34. Royal College of Obstetricians and Gynaecologists. Pandemic H1N1 2009 influenza: Clinical management guidelines for pregnancy. London: RCOG; 2009.

35. Jamieson DJ, Honein MA, Rasmussen SA, Williams JL, Swerdlow DL, Biggerstaff MS, et al. H1N1 2009 influenza virus infection during pregnancy in the USA. Lancet 2009; 374: 451-8. [CrossRef]

36. Rasmussen SA, Jamieson DJ, Bresee JS. Pandemic influenza and pregnant women. Emerg Infect Dis 2008; 14: 95-100. [CrossRef]

37. Singhal S, Sarda N, Arora R, Punia N, Jain A. Clinical profile \& outcome of H1N1 infected pregnant women in a tertiary care teaching hospital of northern India. Indian J Med Res 2014; 139: 454-8.

38. Kim YS, Lee HJ, Chang M, Son SK, Rhee YE, Shim SK. Scrub typhus during pregnancy and its treatment: a case series and review of the literature. Am J Trop Med Hyg 2006: 75; 955-9.

39. Mahajan SK. Scrub Typhus. J Assoc Physic India 2005; 53: 954-8.

40. National AIDS Control Organisation. Annual Report 2009-2010. Department of AIDS Control, Ministry of Health and Family Welfare Govt. of India. Available from: www.nacoonline.org

41. Braitstein P, Brinkhof MW, Dabis F, Schechter M, Boulle A, Miotti $\mathrm{P}$, et al. Mortality of HIV-1-infected patients in the fi rst year of antiretroviral therapy: comparison between low-income and highincome countries. Lancet 2006; 367: 817-24. [CrossRef]

42. Cecatti JG, Souza JP, Oliveira Neto AF, Parpinelli MA, Sousa $\mathrm{MH}$, Say L, Pattinson RC. Pre-validation of the WHO organ dysfunction based criteria for identification of maternal near miss. Reproductive Health 2011; 8: 22. [CrossRef] 